\title{
Amoxicilina en el tratamiento de niños con shigellosis
}

Dres. V. Prado J., J. Cohen V., A. Banfi P.

La Shigellosis continúa siendo un problema endémico en Chile que adquiere mayor relevancia en los períodos estivales. Actualmente en nuestro medio el antimicrobiano de elección es la Ampicilina administrada por vía parenteral, único modo de alcanzar niveles séricos útiles que aseguren una buena respuesta clinico-bacteriológica ${ }^{1}$.

El interés de nuestro trabajo fue evaluar la eficacia de otro antibiótico, la Amoxicilina, de reciente introducción en nuestro medio, el cual, según lo demuestran algunos estudios de farmacocinética $^{2-3}$ administrado por vía oral tiene una mayor absorción a nivel del intestino delgado alcanzando niveles sanguíneos más elevados que Ampicilina, siendo mínima la cantidad de Amoxicilina que se elimina por las deposiciones. Un propósito adicional de nuestra investigación fue el de ensayar la alternativa del uso de un antimicrobiano adminstrado por vía oral en el trat amiento de la Shigellosis en niños.

\section{MATERIAL Y METODO}

Se estudiaron 40 niños hospitalizados por cuadros de Diarrea Aguda y/o Síndrome disentérico en el Hospital Luis Calvo Mackenna, en el período comprendido entre noviembre 1977

Facultad de Medicina Santiago Oriente. Depto. de Salud Pública Unidad Microbiologia. Hospital Luis Calvo Mackenna. y enero 1979 de los cuales se aisló Shigella de las deposiciones.

Los coprocultivos se efectuaron tomando una muestra de deposición recién emitida con tórula de madera y transportada en medio de Cary Blair.

Las muestras fueron sembradas en medio selectivo SS y Mac Conkey

Se estudiaron todas las colonias lactosa negativa en la siguiente serie de medios diferenciales TSI, LIA, MIO, citrato de Simmons y caldo peptonado + urea, aquellas colonias con las características bioquímicas de Shigella se aglutinaron con sueros grupales polivalentes $y$ posteriormente estas cepas fueron referidas al Centro Nacional de Enterobacterias del Instituto Bacteriológico de Chile, para su confirmación.

A cada paciente se le administró Amoxicilina (Amoxil ${ }^{R}$ Beecham) en forma de jarabe en dosis de $50 \mathrm{mg} \times \mathrm{kg} . \mathrm{p} \times$ día; $\mathrm{c} / 8 \mathrm{hrs}$; porvía oral y durante 5 dias.

Diariamente se evaluaron los siguientes parámetros clínicos: fiebre, deshidratación, característica y frecuencia de las deposiciones y curva de peso.

Se efectuaron coprocultivos de control al $6^{\circ}$ día y $15^{\circ}$ día para pesquisar persistencia de Shigella.

Se determinó la CIM de todas las cepas de Shigella frente a los siguientes antimicrobia- 
nos: Amoxicilina, Ampicilina, Gentamicina, Cloramfenicol y Cotrimoxazol, mediante la técnica de dilución en placa utilizando el instrumento de Steers.

$\mathrm{Al}$ inicio y término del tratamiento se efectuaron los siguientes análisis: hemograma, nitrógeno ureico, orina, bilirrubinemia, transami- nasa oxalacética y pirúvica, fosfatasas alcalinas y electrólitos plasmáticos.

No se utilizaron agentes antiespasmódicos ni absorbentes.

Para la evaluación se estableció una escala de cuatro categorías de respuesta clínicobacteriológica definidas como:

\section{CATEGORIAS DE RESPUESTA CLINICO-BATERIOLOGICA}

\begin{tabular}{|c|c|}
\hline MUY BUENA & $\begin{array}{l}\text { Al } 3^{e r} \text { día de tratamiento deposiciones normales; afebril; curva de peso ascenden- } \\
\text { te y coprocultivo negativo al } 6^{\circ} \text { día. }\end{array}$ \\
\hline BUENA & $\begin{array}{l}\text { Al } 4^{\circ} \text { o } 5^{\circ} \text { día de tratamiento deposiciones normales; afebril; curva de peso plana o } \\
\text { ascendente y coprocultivo de control negativo al } 6^{\circ} \text { día. }\end{array}$ \\
\hline REGULAR & $\begin{array}{l}\text { Al } 5^{\circ} \text { dia de tratamiento deposiciones todavía alteradas pero desaparición de ele- } \\
\text { mentos disenteriformes; afebril; curva de peso plana y coprocultivo de control al } \\
6^{\circ} \text { dia negativo. }\end{array}$ \\
\hline MALA & $\begin{array}{l}\text { Al } 5^{\circ} \text { dia de tratamiento deposiciones sin ninguna mejoría; persistencia de fiebre; } \\
\text { curva de peso plana o ascendente y coprocultivo de control al } 6^{\circ} \text { dia positivo o nega- } \\
\text { tivo. }\end{array}$ \\
\hline
\end{tabular}

\section{RESULTADOS}

La tabla 1 muestra las características de edad, sexo y estado nutritivo del grupo estudiado. Más del $80 \%$ de los casos corresponde a lactantes menores de 1 año. La distribución por sexo

\section{Tabla 1}

AMOXICILINA EN SHIGELLOSIS 40 CASOS 1978-1979

CARACTERISTICAS CLINICAS PRINCIPALES

\begin{tabular}{lrr}
\hline 1) EDAD & \multicolumn{1}{c}{$N^{0}$} & \multicolumn{1}{c}{$\%$} \\
\hline$<6$ meses & 16 & 40,0 \\
6 meses 1 día -12 meses & 17 & 42,5 \\
12 meses 1 dia -24 meses & 2 & 5,0 \\
2 años - 4 años & 5 & 12,5 \\
\hline
\end{tabular}

2) $S E X O$

\begin{tabular}{lll}
\hline Masculino & 21 & 52,5 \\
Femenino & 19 & 47,5 \\
\hline
\end{tabular}

3) ESTADO NUTRITIVO

\begin{tabular}{lrr}
\hline Eutróficos & 16 & 40,0 \\
Desnutrición G. I & 15 & 37,5 \\
Desnutrición G. II & 6 & 15,0 \\
Desnutrición G. IIJ & 3 & 7,5 \\
\hline
\end{tabular}

es semejante y en el $60 \%$ de ellos hay algún grado de desnutrición.

La tabla 2 muestra las características del cuadro clínico de los pacientes. El $75 \%$ de ellos

Tabla 2

AMOXICILINA EN SHIGELLOSIS 40 CASOS
$1978-1979$

CARACTERISTICAS CLINICAS PRINCIPALES

\begin{tabular}{|c|c|c|}
\hline 4) Tiempo de evolución de diarrea & $N^{\circ}$ & $\%$ \\
\hline Menos de 2 días & 15 & 37,5 \\
\hline Entre 2 y 7 dias & 15 & 37,5 \\
\hline Más de 7 días & 10 & 25,0 \\
\hline \multicolumn{3}{|l|}{ 5) Caracteristicas de las deposiciones } \\
\hline Síndrome disentérico & 22 & 55,0 \\
\hline \multicolumn{3}{|l|}{ 6) Estado de hidratación } \\
\hline Con deshidratación & 29 & 72,5 \\
\hline \multicolumn{3}{|l|}{ 7) Fiebre } \\
\hline$\geq 37,5^{\circ} \mathrm{C}$ & 30 & 75,0 \\
\hline \multicolumn{3}{|l|}{ 8) Compromiso neurológico } \\
\hline Convulsiones & 5 & 12,5 \\
\hline Hipertonía & 5 & 12,5 \\
\hline Total & 10 & 25,0 \\
\hline
\end{tabular}


tenía un tiempo de evolución de la diarrea de menos de 7 días. La mitad de ellos son síndrome disentérico. Más del $70 \%$ presentó fiebre y algún grado de deshidratación. En la cuarta parte de los pacientes hubo compromiso neurológico.

La tabla 3 muestra que sólo la mitad de los casos presentó alteraciones de la serie blanca del hemograma previo al tratamiento caracterizado por leucocitosis con neutrofilia y desviación a la izquierda.

\section{Tabla 3}

\section{AMOXICILINA EN SHIGELLOSIS 40 CASOS $1978-1979$}

CARACTERISTICAS DE LA SERIE BLANCA EN HEMOGRAMAS PREVIOS AL TRATAMIENTO

\begin{tabular}{lcc}
\hline Serie blanca & $\begin{array}{l}N^{\circ} P a- \\
\text { cientes }\end{array}$ & $\%$ \\
\hline $\begin{array}{l}\text { Leucocitos }>10.000 / \mathrm{mm}^{3} \text { con neutro- } \\
\text { filia* y desviación a la izquierda }\end{array}$ & 21 & 52,5 \\
$\begin{array}{l}\text { Leucocitos }<10.000 / \mathrm{mm}^{*} \text { con fórmula } \\
\text { normal }\end{array}$ & 19 & 47,5 \\
\hline Total & 40 & 100,0 \\
\hline
\end{tabular}

${ }^{*}$ Neutrófilos $\geq 8.000_{i}^{\prime} \mathrm{mm}^{3}$.

Tabla 4

AMOXICILINA EN SHIGELLOSIS 40 CASOS 1978. 1979

EVALUACION BIOQUIMICA

\begin{tabular}{lcc}
\hline Exámenes & $\begin{array}{c}\text { Pretratamiento } \\
\bar{X}\end{array}$ & $\begin{array}{c}\text { Postratamiento } \\
\boldsymbol{X}\end{array}$ \\
\hline N. Lireico mg\% & 4,55 & 6,40 \\
Bilirrubina mg \% & 0,24 & 0,72 \\
TGO LK & 24,0 & 22,0 \\
TGP UK & 22,5 & 21,0 \\
F. alcalinas LB & 5,9 & 7,6 \\
\hline
\end{tabular}

Tabla 5

AMOXICILINA EN SHIGELLOSIS 40 CASOS 1978-1979

SEROTIPOS DE SHIGELLAS AISLADAS

\begin{tabular}{lrr}
\hline Serotipos & $N^{\circ}$ & $\%$ \\
\hline Shigella flexnerii & 30 & 75.0 \\
Shigella sonnei & 8 & 20.0 \\
Shigella boydii & 2 & 5.0 \\
\hline
\end{tabular}

Tabla 6

AMOXICILINA EN SHIGELLOSIS 40 CASOS

RESPUESTA CLINICO BACTERIOLOGICA

\begin{tabular}{lrr}
\hline Respresta & $N^{0}$ & $\%$ \\
\hline Muy buena & 27 & 67,5 \\
Buena & 8 & 20,0 \\
Regular & 4 & 10,0 \\
Mala & 1 & 2,5 \\
\hline
\end{tabular}

La tabla 4 muestra que el promedio de los valores de los exámenes bioquímicos efectuados en el pre y postratamiento está dentro del rango normal.

La tabla 5 muestra que el $75 \%$ de las cepas aisladas de Shigella corresponden al serotipo Flexnerii.

La tabla 6 muestra que el $87,5 \%$ de los pacientes tuvo una respuesta entre muy buena y buena al tratamiento con Amoxicilina.

La tabla 7 muestra que en el $100 \%$ de los casos desapareció la Shigella de las deposiciones después de 5 dias de tratamiento. Es necesario señalar que en el control practicado al $6^{\circ}$ día se aislaron 6 cepas de otras bacterias enteropatógenas: 5 Salmonella Typhimurium, 2 de las cuales se obtuvieron de enfermos que presentaron una

Tabla 7

AMOXICILINA EN SHIGELLOSIS 40 CASOS. 1978-1979 CONT ROLES BACTERIOLOGICOS

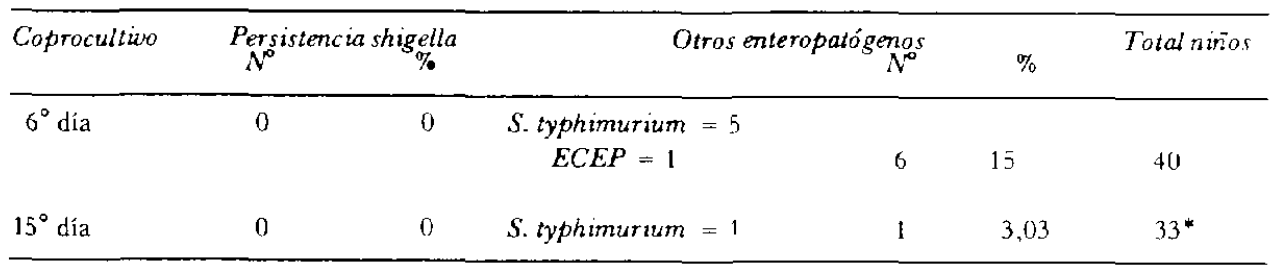

*Niños no acudieron a control. 
buena respuesta y 1 ECEP. A los 15 días una cepa de Salmonella Ty phimurium.

La tabla 8 muestra la CIM de las cepas de Shigella frente a 5 antimicrobianos. Destacamos que el total de las cepas aisladas eran sensi- bles a Amoxicilina. Se consideraron sensibles a Amoxicilina, Ampicilina, Cloramfenicol y Cotrimoxazol aquellas cepas con CIM $\leq 12,5$ $\mathrm{mcg} / \mathrm{ml}$; y a Gentamicina con CIM $\leq 6,12 \mathrm{mcg} /$ $\mathrm{ml}$.

Tabla 8

AMOXICILINA EN SHIGELLOSIS 40 CASOS. 1978-1979

CONCENTRACION INHIBITORIA MINIMA (CIM) EN mcg/ml DE 40 CEPAS DE SHIGELLA FRENTE A 5 ANTIMICROBIANOS

\begin{tabular}{|c|c|c|c|c|c|c|c|}
\hline \multirow{2}{*}{ Antimicrobianos } & \multicolumn{2}{|c|}{$\leq 3,12 \mathrm{mcg} / \mathrm{ml}$} & \multicolumn{2}{|c|}{$6,12-12,5 \mathrm{mcg} / \mathrm{ml}$} & \multicolumn{2}{|c|}{$\geq 25 \mathrm{mcg} / \mathrm{ml}$} & \multirow{2}{*}{$\begin{array}{c}\text { Cepas } \\
\text { sensibles } \\
\%\end{array}$} \\
\hline & $N^{\circ}$ & $\%$ & $N^{\circ}$ & $\%$ & $N^{\circ}$ & $\%$ & \\
\hline Amoxicilina & 33 & 82,5 & 7 & 17,5 & 0 & 0 & 100 \\
\hline Ampicilina & 35 & 87,5 & 5 & 12,5 & 0 & 0 & 100 \\
\hline Cloramfenicol & 32 & 80,0 & 7 & 17,3 & 1 & 2,5 & 95,5 \\
\hline Cotrimoxazol (STM-TM) & 18 & 45.0 & 13 & 32,5 & 9 & 22,5 & 77,5 \\
\hline Gentamicina? & 38 & 95,0 & 0 & 0 & 2 & 5,0 & 95,0 \\
\hline
\end{tabular}

\section{COMENTARIO}

El análisis de los niños con Shigellosis incluidos en nuestro estudio viene a corroborar observaciones anteriores. Así vemos que el mayor porcentaje corresponde a niños menores de 1 año $(82,5 \%)$ demostrando de este modo la mayor suceptibilidad de los lactantes de esta edad a presentar enfermedad clínica; otra caracteristica que habla en este mismo sentido es que una proporción importante de estos niños tenía una evolución previa de por lo menos una semana; mostrando así que la Shigellosis en lactantes no es tan autolimitada como se observa en niños escolares o adultos.

Otros rasgos importantes de destacar es que en concordancia también con observaciones anteriores, aproximadamente la mitad de los pacientes presentaba deposiciones disentéricas y esto no tenía relación con el tiempo de evolción de la diarrea previo al tratamiento. Este hecho habría que atribuirlo en la interacción agente-huésped, a factores de mayor virulencia de las cepas de Shigella o a huéspedes que se defienden mal y en este sentido se le atribuye importancia a los niveles de IgA secretora a nivel intestinal ${ }^{4}$.

Por otra parte en la muestra estudiada comprobamos que un porcentaje de los niños (25\%) presentaban signos neurológicos que se tradujeron en convulsiones tónico-clónicas o hipertonía con rigidez de nuca moderada en respuesta a la acción de endotoxinas, característica que sumada a la existencia de un síndrome disentérico siempre nos hace plantear un a Shigellosis.

El hemograma en estos casos ofreció una ayuda relativa puesto que aproximadamente la mitad de ellos demostró un hemograma normal al comienzo del tratamiento.

En riuestro medio los resultados terapéuticos obtenidos con el uso de Amoxicilina en Shigellosis fueron altamente satisfactorios lo que estaría en discordancia con publicaciones norteamericanas ${ }^{5}$, pero ello se explicaría por las siguientes razones: por una parte los serotipos de Shigella que prevalen en los EE.UU. corresponden al grupo Shigella sonnei y se caracterizan por presentar una elevada resistencia a los antimicrobianos, siendo el aislamiento de Shigella flexnerii de baja frecuencia $25,4 \%^{6}$.

En nuestro pais, en cambio, la incidencia de Shigella sonei es muy baja y así el aislamiento de un $20 \%$ que muestran nuestras observaciones refleja fielmente la frecuencia registrada a través de los años ${ }^{7}$.

En cambio, los serotipos del grupo de Shigella flexnerii son regularmente los aislados con mayor frecuencia $(70-80 \%)$ en nuestro país y estos serotipos "chilenos" tradicionalmen- 
te presentan una buena sensibilidad in vitro a los diferentes antimicrobianos como lo demuestran también nuestros resultados ${ }^{7-8}$. Esto estaría indicando que entre nuestras cepas de Shigella los plasmidios que llevan el factor $R$ y que codifica la multirresistencia a los antimicrobianos tendría una baja difusión.

Asi observamos que el $100 \%$ de las cepas de Shigella aisladas en nuestro estudio eran sensibles a la Amoxicilina, lográndose en todos los casos la desaparición de la Shigella de las deposiciones después de 5 dias de tratamiento. Por lo tanto, en aquellos casos en que la respuesta clínica fue regular o mala esto se debió a factores inherentes al huésped, ya que presentaron infecciones intrahospitalarias intercurrentes entre ellos 3 casos de infección enteral a Salmonella typhimurium; un caso de enteritis por ECEP de serotıpo clásico más una intolerancia secundaria a disacáridos, y un caso de Bronconeumonia intercurrente.

Por último otra ventaja que se advierte con el uso de Amoxicilina se deriva de la mayor vida media que tiene este antimicrobiano ${ }^{2}$ lo cual permite administrarlo $\mathrm{c} / 8 \mathrm{hrs}$. lo que facilita el tratamiento, especialmente en pacientes ambulatorios. Finalmente observamos una muy buena tolerancia y es así como en los 40 niños tratados con Amoxicilina no se detectó efectos adversos, tanto del punto de vista clínico como de parámetros bioquímicos.

\section{CONCLUSION}

Podemos concluir de los resultados obtenidos en nuestra investigación que la Amoxicilina
(Amoxil ${ }^{*}$ Beecham) en dosis de $50 \mathrm{mg} \times \mathrm{Kg}$ $\times$ día administrada por via oral $\mathrm{c} / 8 \mathrm{hrs}$. durante 5 días resulta una alternativa eficaz para el tratamiento de la Shigellosis en nuestro medio.

\section{REFERENCIAS}

1 Haltalm, K.C.; Nelson, J.D.; Hinton, L.V.; Kursmiesz, H.T.; Sladaje M. Comparison of Orally Absorbable and Nonabsorbable Antibiotics in Shigellosis. J. Pediat. 72:708, 1968

- Cordon, R.; Regamey, E.; Kirby, W. Comparative Cilinical Pharmacology of Amoxicil in and Ampicillin Administered Orally. Antimicrob. Ag. Chemother. 1:504. 1972

i Neu, H; Winshell, E. Pharmacological Studies of 6 (D) (-) Alfa Amino p-Hydroxyphenyllacetamido) Penicillanic Arid Humans. Antimicrob. Ag. Chemother. p. 423, 1970

4 OMS. Enterovacunas bacterianas orales. Serie de informes técnicos $\mathrm{N}^{\circ} 500$ Ginebra, 1972

5 Nelson, J; Haltalin, K. Amoxicillin less effective than Ampicillin against Shigella in Vitro and in Vivo: Relationship of Efficacy to activity in serum. J. Infect. Dis 129 (Suppl), p. 22, 1974.

6 MMWR. Shigellosis United States, 1976, 27:10, p. 79, 1978.

7 Prado, V.: Mimica, I. Etiología bacteriana de la Diarrea $A$ guda del Lactante. Rev. Chile Ped. 45: 135, 1974.

${ }^{2}$ Prado, V.; Banfi, A.; Donoso, E. Evaluación Clínico Bacteriológica del uso de Cotrimoxazol en el Tratamiepto de la Shigellosis en lactantes. Rev Chile Ped. 46: 25,1975

* Haltalin, K.; C. Nelson, J.D.; Kusmiesz, H.T.; Honton, L.V. Comparison of Intramuscular and Oral Ampicillin Therapy for Shigellosis. J. Pediat. 73: $617,1968$.

\footnotetext{
* Esta investigación fue desarrollada ron un grant otorgado por Laboratorios Beecham.
} 